\title{
Is There a Role for Long-Term Silicone Oil Tamponade for More than Twelve Months in Vitreoretinal Surgery?
}

\author{
Theodor Stappler George Morphis Cristina Irigoyen Heinrich Heimann
}

St Paul's Eye Unit, Royal Liverpool University Hospital, Liverpool, UK

\section{Key Words}

Silicone oil · Tamponade • Vitreoretinal surgery

\begin{abstract}
Despite modern and sophisticated vitreoretinal techniques, the authors are convinced that an underreported patient group exists, for whom long-term silicone oil tamponade is unavoidable. We conducted a literature review of the current evidence base in order to provide guidance on the ocular tolerance and side effects of long-term silicone oil, weighing up benefits against complications as well as providing an outlook on future silicone oils with improved physical properties. We advocate the removal of silicone oil in all cases; however, one has to recognise that long-term silicone oil tamponade may have to be considered as a measure of last resort for selected patients. There is a clinical need to develop novel, emulsification-resistant tamponades.
\end{abstract}

Copyright $\odot 2011$ S. Karger AG, Basel

\section{Background}

Despite the increased sophistication of vitreoretinal techniques and endotamponades ever since Cibis et al. [1] first pioneered the concept of 'liquid silicone oil' in the treatment of retinal detachments almost four decades ago, surgical outcomes are still far from having attained complete success. As surgery is attempted in ever more complex cases, and as there is an expansion of indications for the intraocular use of silicone oil at the same time [2], this situation is unlikely to change. Historically, silicone oil tamponade was mainly intended for complex retinal detachments [3] with aggravating factors such as proliferative vitreoretinopathy (PVR) $[4,5]$ and tractional retinal detachments associated with proliferative diabetic retinopathy $[6,7]$. However, indications for the use of silicone oil expanded over time to include macular holes [8, 9], myopic foveoschisis [10, 11], optic disc pits [12], uveitis $[13,14]$, acute retinal necrosis [15], hypotony [14] and trauma [16]. With such an ever-increasing number of patients eligible, silicone oil-related issues including the management of its complications have become relevant factors in the daily practice of vitreoretinal specialists and general ophthalmologists alike. The use of silicone oil is accompanied by a specific risk profile which includes glaucoma, emulsification, inflammation, corneal decompensation/band keratopathy, cataract and the proliferation of fibrocellular membranes. Most authors therefore aim to remove the silicone oil from the vitreous cavity within a few months. Despite these recommendations, there still is a distinct group of patients in real-life practice who, for various reasons, end up having to live with long-term silicone oil tamponade. Such groups of

\section{KARGER}

Fax +4161306 1234

E-Mail karger@karger.ch

www.karger.com
(C) 2011 S. Karger AG, Basel

$0030-3755 / 11 / 2265-0036 \$ 38.00 / 0$

Accessible online at:

www.karger.com/oph
Theodor Stappler

St Paul's Eye Unit

Royal Liverpool University Hospital

Liverpool L7 8XP (UK)

E-Mail TheodorStappler@web.de 
patients consist of those declining further surgery following multiple vitreoretinal procedures for retinal detachment, attempted oil removal, recurrent vitreous haemorrhages for proliferative diabetic retinopathy and hypotony after retinectomy as well as of patients with learning difficulties who are unable to fully cooperate in their care. Often such patients are referred to as surgical failures [17]. There is a conspicuous lack of published evidence regarding this less-talked-about patient group. We conducted a literature review of the current evidence base in order to provide guidance on the ocular tolerance and safety of long-term silicone oil, weighing up benefits against complications as well as providing an outlook on future silicone oils with improved physical properties.

\section{Rationale for the Use of Silicone Oil as a Long-Term Tamponade}

It is the oil's specific ability to lie in situ for extended periods of time which can still influence biological processes like PVR to play out, over which there is otherwise only very limited therapeutic control. A reaction like PVR can therefore run its course, while effective retinal tamponade is provided by the oil [18]. One main advantage of oil is that it is chemically inert as linear unbranched polydimethylsiloxanes $\mathrm{CH}_{3}\left[\mathrm{Si}\left(\mathrm{CH}_{3}\right)_{2} \mathrm{O}\right]_{n} \mathrm{Si}\left(\mathrm{CH}_{3}\right)_{3}$. Its hydrophobic molecular structure does not allow it to mix with water and provides for a stable interface between the two phases. It works by occluding breaks and preventing the communication of fluid between the subretinal and vitreous spaces, thus allowing the retina to attach to the underlying retinal pigment epithelium by means of the latter's active transport of subretinal fluid out of the subretinal space. Unlike gas, its density is only slightly lower than that of water (i.e. $0.97 \mathrm{~g} / \mathrm{cm}^{3}$ ). The resulting shape of the oil bubble is mainly determined by interfacial tension and buoyancy, which means that relatively more of the volume of the silicone oil is used to form the interface with the surrounding aqueous phase, and less of the volume is being used to provide tamponade. This makes silicone oil an inherently inefficient tamponade, and it is therefore imperative that an almost complete fill of the vitreous cavity is achieved [19]. This applies to all silicone oil-based endotamponades, whether they are 'light' or 'heavy'. Historically, the development of heavy tamponades has included the use of perfluorocarbon liquids, which are now mainly used as intraoperative tools, but in some rare cases as endotamponades for short-term use [20]. Oxane HD (Bausch \& Lomb, Toulouse, France) was the first silicone oil-based heavy tamponade. Its specific gravity had been increased by its mixture with RMN-3, a fluorinated and hydrocarbonated olefin $(88.1 \%$ Oxane $5,700 \mathrm{cSt}$ and $11.9 \% \mathrm{RMN}-3$ ) [21]. It was, however, relatively light (specific gravity: $1.02 \mathrm{~g} / \mathrm{ml}$ ) and has remained controversial due to concerns about its complication profile $[22,23]$. Densiron 68 (Fluoron Co., Neu-Ulm, Germany) represents a mixture of $\mathrm{F}_{6} \mathrm{H}_{8}(30.5 \%)$ with 5,000$\mathrm{mPa} \cdot \mathrm{s}$ silicone oil (69.5\%). Its specific gravity is $1.06 \mathrm{~g} / \mathrm{ml}$, its viscosity is $1,349 \mathrm{mPa} \cdot \mathrm{s}$, its refractive index is 1.39 and its interfacial tension $40.82 \mathrm{mN} / \mathrm{m}$. Since the first pilot trial [24], large patient series have been published [25, 26], and it was the heavy oil investigated in the European multicentre randomised controlled trial called the 'HSOStudy' [27]. Until now there has been no alternative to silicone oil-based tamponades as they remain the only agents licensed to provide long-term tamponade for the retina.

\section{Long-Term Silicone Oil Stability}

One of the foremost concerns when using a medical device is its long-term integrity. Lakits et al. [28] used highly sensitive techniques such as gas chromatography/ mass spectroscopy to detect and characterise low-molecular-weight components in silicone oil that had been removed from patients' eyes for a variety of indications such as PVR, proliferative diabetic retinopathy and tractional retinal detachment after central retinal vein occlusion. In addition, gel permeation chromatography was used to determine the molecular weight distribution of the silicone oils. Functional groups of silicone oils were quantified and further characterised by infrared spectroscopy and ${ }^{1} \mathrm{H}$ nuclear magnetic resonance spectroscopy. It was concluded that $5,000-\mathrm{mPa} \cdot \mathrm{s}$ silicone oils were chemically stable in the human eye and did not undergo chemical modification. In contrast, Tomlins et al. [29] analysed droplets of emulsified Oxane HD taken from the anterior chamber of 2 patients with complex retinal detachments who had been treated with this heavy oil. Nuclear magnetic resonance analysis of the samples removed from the anterior segment of both eyes was mainly silicone oil with only trace amounts of RMN-3. In addition, samples taken from different areas of an unused syringe with Oxane HD demonstrated varying concentrations of the RMN-3 compound within the silicone oil. This proved that the mixture of RMN-3 and silicone oil was not homogeneous either in vitro or in vivo. In this context the finding of a 'floating' bubble of heavy oil in 
the anterior chamber by Lai et al. [23] can be well explained, and such findings underscore the vital need for long-term follow-up data.

\section{Guidance on the Use of Long-Term Silicone Oil Tamponade}

The authors are convinced that an underreported patient group exists for whom a decision has been made not to conduct further procedures, which results in these patients having to live with long-term silicone oil tamponade. Reasons for refraining from further surgery are plentiful and they are usually based on concerns about a worsening of the anatomical situation once oil is removed, which itself may necessitate additional surgery including the reinstallation of an intraocular silicone oil tamponade. Such patients are being seen on a regular basis in most vitreoretinal tertiary centres, and only few studies have been published so far that can provide guidance for these patients' needs.

\section{Anatomical and Functional Success Rate versus}

\section{Complications: 'To Remove or Not to Remove'}

The recurrence of retinal detachment secondary to fibrovascular proliferation, hypotony with subsequent phthisis as well as neovascular glaucoma and fibrinoid syndrome in diabetics are only some of the many consequences should the initial vitrectomy involving the primary silicone oil prove unsuccessful. Redetachment rates can be quite variable, starting from $9 \%$ [30] over 25\% [31] and sometimes reaching 66\% [32]. This considerable variation reflects the inhomogeneous case mix of the underlying diseases necessitating silicone oil surgery. There is no mandatory time period after which silicone oil should be removed and its indication is entirely at the vitreoretinal surgeon's discretion. Hutton et al. [33] could not find a difference in the rate of redetachment when silicone oil was removed before or after 6 months. Such results were later corroborated by Falkner et al. [34]. However, it is most likely that the retina redetaches within the first 3 months following silicone oil removal. The same group of authors later found a beneficial effect in the simultaneous application of a 360-degree endolaser barrier [35]. Definitions of success can vary and be described as complete retinal reattachment without tamponade, complete retinal reattachment with tamponade and retinal redetachment. Most authors prefer to classify only retinal reattachments without tamponade as successful. Rinkoff et al. [17] published a case series on 10 patients with PVR- rhegmatogenous retinal detachment following vitrectomy for proliferative diabetic retinopathy. In this series, only $30 \%$ of cases achieved retinal reattachment. Reattachment rates in Yeo et al. [36] from a series of 23 eyes with proliferative diabetic retinopathy were as high as 70\%. Azen et al. [37] and Scott et al. [38] reported successful retinal reattachment at the last follow-up visit in 57\% of a large case series of 359 eyes of 340 patients. However, the rate of macular reattachment was higher at $74 \%$. Scott et al. [38] had a mix of more severe cases, also including retinal detachment associated with cytomegalovirus retinitis or non-cytomegalovirus necrotising retinitis, in addition to proliferative diabetic retinopathy, giant retinal tear, PVR and even ocular trauma. In their series, 127 patients (132 eyes) underwent vitrectomy including silicone oil. The reattachment rate of eyes undergoing the first operation or after previously failed vitrectomy was 56/116 (48\%) and 8/16 (50\%), respectively.

Castellarin et al. [6] in their series of 23 eyes with vitrectomy and long-term silicone oil infusion for treatment of proliferative diabetic retinopathy reported anatomic success in $75 \%$ of eyes with one operation and in $73 \%$ with a second operation after a failed vitrectomy. However, they defined anatomical and surgical success as retinal reattachment with silicone oil in situ. The mean followup time in the above series was 5.4 months, but 4 eyes were followed up for more than 12 months with only $50 \%$ anatomical success. A similar definition of anatomical success can be found with Shen and Yang [39], who reported on a series of 54 eyes which underwent primary pars plana vitrectomy for complex retinal detachment in proliferative diabetic retinopathy with silicone oil insertion. The mean follow-up time was 28 months with anatomic success at $83.3 \%$.

Functional results are generally very poor; however, according to Scott et al. [38] there is a clear correlation between the removal of silicone oil and improved visual acuity. The achievement of vision better than 5/200 is defined as ambulatory vision. Azen et al. [37] achieved such vision in $24 \%$ of cases, and Scott et al. [38] reported final ambulatory vision in $45 \%$. More patients achieved ambulatory vision in primary success cases (48\%) compared with reoperated cases (25\%). These differences were not statistically significant $(\mathrm{p}=0.1)$. Only $2(20 \%)$ of the cases of Rinkoff et al. [17] regained ambulatory vision. Similarly, Yeo et al. [36] reported a final visual acuity of 5/200 or better for $5(22 \%)$ of 23 eyes. Interestingly, in the case series of Castellarin et al. [6] a similar proportion of 5 eyes (22\%) achieved vision greater than $5 / 200$, despite different measures of success, essentially with 'permanent' silicone oil. 


\section{Trauma}

Szurman et al. [16] reported on 23 patients with severe intraocular foreign body injuries that had primary vitrectomy with silicone oil tamponade. Their anatomic success rate was $83 \%$ with a mean tamponade duration of 9.1 months. Useful visual acuity of 20/400 was preserved in $55 \%$ of patients. PVR occurred in $70 \%$ of eyes. Three patients (13\%) developed permanent glaucoma. Finally, eyes with permanent silicone oil in these series did not show a statistically significant risk of developing silicone oilrelated keratopathy.

\section{Complications}

The prolonged contact with silicone oil in the eye has been linked to various complications which are the main rationale for its recommended removal. Frequent complications include migration to the anterior chamber, glaucoma [40, 41], emulsification, inflammation, corneal decompensation, band keratopathy and cataract.

Other less common complications are hypotony and unexplained visual loss, and extremely rare complications are migration of silicone oil into the suprachoroidal space [42] as well as migration into the lateral ventricles of the brain [43].

\section{Glaucoma}

The Silicone Study [44] reports a higher incidence of chronically elevated intraocular pressure (IOP) in the silicone oil group compared with the gas group (8 vs. $2 \%$ ). According to Ghazi-Nouri et al. [40] and Ichhpujani et al. [41], four different mechanisms have been proposed for the pathogenesis of silicone oil-related glaucoma: (1) overfill with total anterior chamber fill leads to an openangle glaucoma due to mechanical obstruction of outflow; (2) pupillary block with silicone oil incites angle closure glaucoma; (3) emulsification of silicone oil into microdroplets may sweep into the trabecular meshwork with the development of secondary open-angle glaucoma, or (4) inflammation or exacerbation of preexisting glaucoma occurs. Emulsification of the silicone oil in the microglobules has been associated with a rise in IOP [45, 46]. It has been hypothesised that these microglobules mechanically obstruct the trabecular meshwork. First reported by Cibis et al. [1], the rates of raised IOP range from $2.2 \%$ in 6 months [47] to $56 \%$ in 8 months [48]. Valone and McCarthy [49] have documented a somewhat lower prevalence of about $10 \%$, which they attributed to improved manufacturing and the absence of low-molecular-weight silicone oil. For heavy tamponades such as Densiron $68[26,50]$ and Oxane HD [21] similar glauco- ma rates have been described as with conventional silicone oil [51]. Unfortunately, the prognostic factors for IOP elevation continue to remain unclear.

\section{Silicone Oil Neuropathy}

In addition to glaucomatous pressure-dependent optic neuropathy, there may also be a direct deleterious effect of silicone oil on the optic nerve. As early as 1 month after instillation into the eye, silicone oil can be found in the optic nerve with elevated IOP. Silicone oil may enter the optic nerve after longstanding silicone oil endotamponade and elevated IOP [52]. The mechanism may be similar to the migration of acid mucopolysaccharides from the vitreous into the optic nerve in non-vitrectomised eyes with markedly elevated IOP (Schnabel's cavernous optic nerve atrophy). In a study on postmortem eyes, however, Knecht et al. [53] could not establish a pressure-related connection.

\section{Band Keratopathy}

Silicone oil damages the cornea. Specular microscopic studies in rabbit eyes have shown the main corneal complication to be endothelial cell damage including decreased cell density by $40 \%$, pleomorphism and necrosis [54]. If allowed to enter the anterior chamber, silicone oil will eventually lead to corneal endothelial cell damage, oedema or band keratopathy. Rates of keratopathy after silicone oil injection have been reported to range from 4.5 to $63 \%$ [34]. Silicone oil in the anterior chamber may act as a physical barrier and interfere with corneal homoeostasis. When the oil is removed later, damaged endothelium may allow for excess stromal hydration and lead to corneal oedema. Friberg and Guibord [55] postulated that endothelial cell loss after vitreoretinal surgery is exacerbated by long-term silicone oil retention. The corneal endothelial cell damage is probably cumulative from procedure to procedure. Endothelial cell loss may be more pronounced in aphakic eyes. However, in the longterm case series of Castellarin et al. [6] keratopathy was only noted in 2 eyes ( $8 \%)$.

\section{Cataract}

The rate of cataract formation varies in the literature between 78 and 100\% [56]. However, given time all lenses eventually form ever denser cataracts.

\section{Hypotony}

In the Silicone Study [44] hypotony was present in 31\% of patients treated with gas, and only in $18 \%$ if treated with silicone oil. Hypotony can result from cyclitic mem- 
brane formation with ciliary body detachment or atrophy [57]. Castellarin et al. [6] reported hypotony (defined as IOP $\leq 5 \mathrm{~mm} \mathrm{Hg}$ ) at $22 \%$. However, Yeo et al. [36] had no cases of hypotony in their series.

\section{Future Considerations}

Even though ideally this group of patients should not exist, we advocate that the vitreoretinal surgeon aims to remove silicone oil in all cases; however, long-term silicone oil tamponade may be unavoidable and should only be considered as a measure of last resort for selected patients who, for various reasons, have to retain intraocular silicone oil for extended periods of time, for years and sometimes decades. The authors therefore postulate a clinical need to improve currently available tamponades and to address their shortcomings. A first step in improving emulsification resistance was to remove low-molecular-weight chains and increase viscosity. However, there is still no definitive answer by clinical trial comparing different-viscosity silicone oils. Some authors favour 5,000 -cSt oil [58], others seem to see advantages in using 1,000 -cSt oil [59].

Pragmatically, viscosity cannot be increased ad infinitum and comes at the price of poor handling by the surgeon during injection as well as removal [60]. This problem is exacerbated by the growing trend towards small-gauge sutureless vitrectomy since, according to Poiseuille's law, the radius of a given infusion cannula represents the limiting factor for the injectability of fluids such as silicone oils. The next logical step in the design of silicone oils is to add emulsification resistance 'by design'. One promising approach is the addition of a small percentage of very-high-molecular-weight silicone oil into standard 1,000-cSt oil, which aims to alter the extensional viscosity of the resulting oil such that emulsification is greatly reduced in vitro. One such novel oil is Siluron $2000^{\circledR}$, which combines easy injectability with increased emulsification resistance in vitro. A recent in vitro study by Caramoy et al. [61] concludes that: 'New low-viscosity silicone oils show reduced emulsification similar to that of 5,000 cSt oils. In the future, it may be possible to avoid using 5,000 cSt oils. The findings may foster silicone oil surgery in general and in particular the application of small-incision techniques.'

With silicone oil surgery entering its sixth decade and being used for ever more diverse indications, we are eagerly awaiting whether these promising in vitro physical properties of such 'designer silicone oils' translate into long-term clinical progress.

\section{Disclosure Statement}

The authors have no conflict of interest with the presented material.

\section{References}

$>1$ Cibis PA, Becker B, Okun E, Canaan S: The use of liquid silicone in retinal detachment surgery. Arch Ophthalmol 1962;68:590-599.

$>2$ Heimann H: Alternative indications for the use of heavy silicone oil tamponades (in German). Klin Monbl Augenheilkd 2009;226: 713-717.

3 Lucke KH, Foerster MH, Laqua H: Longterm results of vitrectomy and silicone oil in 500 cases of complicated retinal detachments. Am J Ophthalmol 1987;104:624-633.

$>4$ Gonvers M, Thresher R: Temporary use of silicone oil in the treatment of proliferative vitreoretinopathy: an experimental study with a new animal model. Graefes Arch Clin Exp Ophthalmol 1983;221:46-53.

5 Laqua H: Current concepts in the management of complex retinal detachments. Trans Ophthalmol Soc UK 1983;103:133-138.

$\checkmark 6$ Castellarin A, Grigorian R, Bhagat N, del Priore L, Zarbin MA: Vitrectomy with silicone oil infusion in severe diabetic retinopathy. Br J Ophthalmol 2003;87:318-321.
Karel I, Kalvodova B: Long-term results of pars plana vitrectomy and silicone oil for complications of diabetic retinopathy. Eur J Ophthalmol 1994;4:52-58.

$>8$ Wolfensberger TJ, Gonvers M: Surgical treatment of retinal detachment owing to macular hole. Semin Ophthalmol 2000;15:122-127.

$\checkmark 9$ Goldbaum MH, McCuen BW, Hanneken AM, Burgess SK, Chen HH: Silicone oil tamponade to seal macular holes without position restrictions. Ophthalmology 1998;105: 2140-2147, discussion 2147-2148.

10 Scholda C, Wirtitsch M, Biowski R, Stur M: Primary silicone oil tamponade without retinopexy in highly myopic eyes with central macular hole detachments. Retina 2005;25: 141-146.

$>11$ Soheilian M, Ghaseminejad AK, Yazdani S, Ahmadieh H, Azarmina M, Dehghan MH, Moradian S, Anisian A, Peyman GA: Surgical management of retinal detachment in highly myopic eyes with macular hole. Ophthalmic Surg Lasers Imaging 2007;38:15-22.
12 Ghosh YK, Banerjee S, Konstantinidis A, Athanasiadis I, Kirkby GR, Tyagi AK: Surgical management of optic disc pit associated maculopathy. Eur J Ophthalmol 2008;18: 142-146.

13 Morse LS, McCuen BW 2nd: The use of silicone oil in uveitis and hypotony. Retina 1991; 11:399-404.

14 Kapur R, Birnbaum AD, Goldstein DA, Tessler HH, Shapiro MJ, Ulanski LJ, Blair MP: Treating uveitis-associated hypotony with pars plana vitrectomy and silicone oil injection. Retina 2010;30:140-145.

15 Gerling J, Neumann-Haefelin D, Seuffert HM, Schrader W, Hansen LL: Diagnosis and management of the acute retinal necrosis syndrome. Ger J Ophthalmol 1992;1:388-393.

16 Szurman P, Roters S, Grisanti S, Aisenbrey S, Rohrbach JM, Warga M, Gelisken F, Spitzer MS, Bartz-Schmidt KU: Primary silicone oil tamponade in the management of severe intraocular foreign body injuries: an 8-year follow-up. Retina 2007;27:304-311. 
$\checkmark 17$ Rinkoff JS, de Juan E Jr, McCuen BW 2nd: Silicone oil for retinal detachment with advanced proliferative vitreoretinopathy following failed vitrectomy for proliferative diabetic retinopathy. Am J Ophthalmol 1986; 101:181-186.

18 Kirchhof B: Strategies to influence PVR development. Graefes Arch Clin Exp Ophthalmol 2004;242:699-703.

19 Fawcett IM, Williams RL, Wong D: Contact angles of substances used for internal tamponade in retinal detachment surgery. Graefes Arch Clin Exp Ophthalmol 1994;232: 438-444.

-20 Bottoni F, Sborgia M, Arpa P, de Casa N, Bertazzi E, Monticelli M, de Molfetta V: Perfluorocarbon liquids as postoperative short-term vitreous substitutes in complicated retinal detachment. Graefes Arch Clin Exp Ophthalmol 1993;231:619-628.

21 Wolf S, Schön V, Meier P, Wiedemann P: Silicone oil-RMN3 mixture ('heavy silicone oil') as internal tamponade for complicated retinal detachment. Retina 2003;23:335-342.

22 Theelen T, Tilanus MA, Klevering BJ: Intraocular inflammation following endotamponade with high-density silicone oil. Graefes Arch Clin Exp Ophthalmol 2004;242: 617-620.

23 Lai WW, Wong D, Li KK, Leow PL: Emulsification and inverted hypopyon formation of Oxane HD in the anterior chamber. Graefes Arch Clin Exp Ophthalmol 2008;246:16331635.

24 Wong D, van Meurs JC, Stappler T, Groenewald C, Pearce IA, McGalliard JN, Manousakis E, Herbert EN: A pilot study on the use of a perfluorohexyloctane/silicone oil solution as a heavier than water internal tamponade agent. Br J Ophthalmol 2005;89:662-665.

$\checkmark 25$ Heimann H, Stappler T, Wong D: Heavy tamponade. 1. A review of indications, use, and complications. Eye (Lond) 2008;22: 1342-1359.

-26 Stappler T, Heimann H, Wong D, Gibran SK, Groenewald C, Pearce IA: Heavy tamponade. 2. Densiron 68 in routine clinical practice: anatomical and functional outcomes of a consecutive case series. Eye (Lond) 2008; 22:1360-1365.

-27 Joussen AM, Kirchhof B, Schrage N, Ocklenburg C, Hilgers RD: Heavy silicone oil versus standard silicone oil as vitreous tamponade in inferior PVR (HSO Study): design issues and implications. Acta Ophthalmol Scand 2007;85:623-630.

28 Lakits A, Nennadal T, Scholda C, Knaus S, Gruber H: Chemical stability of silicone oil in the human eye after prolonged clinical use. Ophthalmology 1999;106:1091-1100. 29 Tomlins PJ, Woodcock MG, Spencer N,
Kirkby GR: Nuclear magnetic resonance analysis of emulsified silicone oil RMN-3 (Oxane HD). Br J Ophthalmol 2007;91:13791381.

-30 Zilis JD, McCuen BW 2nd, de Juan E Jr, Stefansson E, Machemer R: Results of silicone oil removal in advanced proliferative vitreoretinopathy. Am J Ophthalmol 1989;108:1521.

31 Casswell AG, Gregor ZJ: Silicone oil removal. II. Operative and postoperative complications. Br J Ophthalmol 1987;71:898-902.

32 Sandner D, Herbrig E, Engelmann K: Highdensity silicone oil (Densiron) as a primary intraocular tamponade: 12-month followup. Graefes Arch Clin Exp Ophthalmol 2007; 245:1097-1105.

- 33 Hutton WL, Azen SP, Blumenkranz MS, Lai MY, McCuen BW, Han DP, Flynn HW Jr, Ramsay RC, Ryan SJ: The effects of silicone oil removal. Silicone Study Report 6. Arch Ophthalmol 1994;112:778-785.

34 Falkner CI, Binder S, Kruger A: Outcome after silicone oil removal. Br J Ophthalmol 2001;85:1324-1327.

- 35 Falkner-Radler CI, Smretschnig E, Graf A, Binder S: Outcome after silicone oil removal and simultaneous $360^{\circ}$ endolaser treatment. Acta Ophthalmol 2011;89:e46-e51.

- 36 Yeo JH, Glaser BM, Michels RG: Silicone oil in the treatment of complicated retinal detachments. Ophthalmology 1987;94:11091113.

37 Azen SP, Scott IU, Flynn HW Jr, Lai MY, Topping TM, Benati L, Trask DK, Rogus LA: Silicone oil in the repair of complex retinal detachments: a prospective observational multicenter study. Ophthalmology 1998;105: 1587-1597.

-38 Scott IU, Flynn HW, Lai M, Chang S, Azen SP: First operation anatomic success and other predictors of postoperative vision after complex retinal detachment repair with vitrectomy and silicone oil tamponade. Am J Ophthalmol 2000;130:745-750.

39 Shen YD, Yang CM: Extended silicone oil tamponade in primary vitrectomy for complex retinal detachment in proliferative diabetic retinopathy: a long-term follow-up study. Eur J Ophthalmol 2007;17:954-960.

40 Ghazi-Nouri SM, Vakalis AN, Bloom PA, Bunce C, Charteris DG: Long-term results of the management of silicone oil-induced raised intraocular pressure by diode laser $\mathrm{cy}$ cloablation. Eye (Lond) 2005;19:765-769.

-41 Ichhpujani P, Jindal A, Jay Katz L: Silicone oil induced glaucoma: a review. Graefes Arch Clin Exp Ophthalmol 2009;247:1585-1593.

42 Patel AK, Zambarakji HJ, Charteris DG, Sullivan PM: Suprachoroidal silicone oil: recognition and possible mechanisms. Eye (Lond) 2006;20:854-856.

43 Eller AW, Friberg TR, Mah F: Migration of silicone oil into the brain: a complication of intraocular silicone oil for retinal tamponade. Am J Ophthalmol 2000;129:685-688.

44 Barr CC, Lai MY, Lean JS, Linton KL, Trese M, Abrams G, Ryan SJ, Azen SP: Postoperative intraocular pressure abnormalities in the Silicone Study. Silicone Study Report 4. Ophthalmology 1993;100:1629-1635.

45 Moisseiev J, Barak A, Manaim T, Treister G: Removal of silicone oil in the management of glaucoma in eyes with emulsified silicone. Retina 1993;13:290-295.

-46 la Heij EC, Hendrikse F, Kessels AG: Results and complications of temporary silicone oil tamponade in patients with complicated retinal detachments. Retina 2001;21:107-114.

47 Unosson K, Stenkula S, Törnqvist P, Weijdegård L: Liquid silicone in the treatment of retinal detachment. Acta Ophthalmol (Copenh) 1985;63:656-660.

48 de Corral LR, Cohen SB, Peyman GA: Effect of intravitreal silicone oil on intraocular pressure. Ophthalmic Surg 1987;18:446-449.

49 Valone J Jr, McCarthy M: Emulsified anterior chamber silicone oil and glaucoma. Ophthalmology 1994;101:1908-1912.

50 Stappler T, Heimann H, Gibran SK, Groenewald C, Pearce IA, Wong D: Densiron-68 heavy silicone oil in cases of PVR: anatomic and functional outcomes (in German). Ophthalmologe 2009; 106:320-326.

51 Joussen AM, Wong D: The concept of heavy tamponades: chances and limitations. Graefes Arch Clin Exp Ophthalmol 2008;246: 1217-1224.

52 Shields CL, Eagle RC Jr: Pseudo-Schnabel's cavernous degeneration of the optic nerve secondary to intraocular silicone oil. Arch Ophthalmol 1989;107:714-717.

53 Knecht P, Groscurth P, Ziegler U, Laeng HR, Jaggi GP, Killer HE: Is silicone oil optic neuropathy caused by high intraocular pressure alone? A semi-biological model. Br J Ophthalmol 2007;91:1293-1295.

54 Sternberg P Jr, Hatchell DL, Foulks GN, Landers MB 3rd: The effect of silicone oil on the cornea. Arch Ophthalmol 1985;103:9094.

55 Friberg TR, Guibord NM: Corneal endothelial cell loss after multiple vitreoretinal procedures and the use of silicone oil. Ophthalmic Surg Lasers 1999;30:528-534.

56 Larkin GB, Flaxel CJ, Leaver PK: Phacoemulsification and silicone oil removal through a single corneal incision. Ophthalmology 1998;105:2023-2027.

57 Sugar HS, Okamura ID: Ocular findings six years after intravitreal silicone injection. Arch Ophthalmol 1976;94:612-615.

58 Scott IU, Flynn HW Jr, Murray TG, Smiddy WE, Davis JL, Feuer WJ: Outcomes of complex retinal detachment repair using 1,000vs 5,000-centistoke silicone oil. Arch Ophthalmol 2005; 123:473-478.

-59 Soheilian M, Mazareei M, Mohammadpour M, Rahmani B: Comparison of silicon [sic!] oil removal with various viscosities after complex retinal detachment surgery. BMC Ophthalmol 2006;6:21.

60 Williams RL, Day MJ, Garvey MJ, Morphis G, Irigoyen C, Wong D, Stappler T: Injectability of silicone oil-based tamponade agents. Br J Ophthalmol 2011;95:273-276.

61 Caramoy A, Schröder S, Fauser S, Kirchhof $B$ : In vitro emulsification assessment of new silicone oils. Br J Ophthalmol 2010;94:509512 . 